\title{
Salivary clearance of sugar before and after insertion of fixed partial dentures
}

\author{
Serpil Karaoglanoglu ${ }^{\mathrm{a}}$, Zeynep Yesil Duymus ${ }^{\mathrm{b}}$, Nilgun Akgul $^{\mathrm{c}}, \mathrm{Nur}_{\mathrm{O}}$ Ozdabak ${ }^{\mathrm{d}}$, Nilgun Seven ${ }^{\mathrm{c}}$, \\ Fatma Ozabacygile \\ ${ }^{a}$ Atatuerk Education and Research Hospital, Ankara 9031206530; ' Department of Prosthodontics, \\ ${ }^{c}$ Department of Operative Dentistry, Faculty of Dentistry, ${ }^{e}$ Department of Biochemistry, Faculty of \\ Medicine, Atatuerk University, Erzurum 9044225240; ${ }^{d}$ Department of Operative Dentistry, Faculty \\ of Dentistry, Yeditepe University, Istanbul 9021634083, Turkey
}

\begin{abstract}
Background: The development of carious lesions is dependent on the presence of acid-producing microflora in the mouth. The activity of these plaque bacteria is dependent on sugar, which diffuses from the saliva following carbohydrate intake. The sugar serves as a substrate for fermentation, producing organic acids that demineralize tooth enamel. Elimination of the sugar from the mouth is accomplished by dilution with newly secreted saliva, a process generally referred to as sugar clearence.

Objectives: Determine if fixed partial prosthodontic treatment affects the length of salivary sugar clearance. Materials and methods: Fifteen male subjects age between 21 and 32, and requiring 10 porcelain fixed partial dentures were included in this study. Before receiving their dentures, the subjects, rinsed with a $10 \%$ sucrose solution for 30 seconds then gave saliva samples. The prpcedure was repeated one month after the dentures were put in place. The length of sugar clearance was calculated.

Results: Salivary sugar was cleared in $14.89 \pm 0.89$ minutes before the denture application and in $18.86 \pm 0.90$ minutes after denture treatment. The initial sucrose concentration was $113.63 \pm 1.29 \mathrm{mmol} / \mathrm{L}$ before the dentures and $142.99 \pm 10.82 \mathrm{mmol} / \mathrm{L}$ after the dentures.

Conclusion: The use of fixed partial dentures does not affect the time required to clear salivary sugar or the level of the initial sucrose concentration.
\end{abstract}

Keywords: Fixed partial dentures, oral sugar clearance, saliva

Dental caries develops when acid-producing microflora and plaque are present in the mouth [1]. The presence of prostheses and various appliances can lead to an increase in this flora [2-4]. Improperly prepared prosthodontics may prevent the mouth from being cleaned effectively and, thus, lead to plaque retention and the formation of areas amenable to collection of these microorganisms [5].

Dental caries occurs as a result of the organic acids that emerge from microbial fermentation of carbohydrates. Depending on their concentration in plaque, acids lead to demineralization by diffusing into

Correspondence to: Dr. Zeynep Yesil Duymus Atatuerk Universitesi Dis Hekimligi Fakueltesi Protetik Dis Tedavisi, Erzurum 9044225240, Turkey. E-mail: zyesilz@hotmail.com the enamel and dentin [6]. The amount of acid produced varies depending on the type and concentration of fermentable carbohydrates that the bacteria use as substrates. Sugar can be removed from the mouth by means of newly secreted saliva, in a process known as sugar clearance [7]. A variety of factors affects the clearance of sugar from saliva, including the amount of saliva secretion, oral hygiene, and the ability of the lip and tongue to coordinate [8-11]. The goal of this study was to investigate whether the application of fixed partial dentures leads affects the time needed to clear sugar from saliva.

\section{Materials and methods}

The study was carried out using 15 male subjects between the ages of 21 and 32, who had at least 10 
crowns or indications of porcelain fixed partial restorations. The present study was approved by the Ethics Committee of the Faculty of Denstry, Atatürk University. All subjects provided written consent prior to the study.

The sugar-cleaning periods of these subjects were determined before application of the prosthesis and one month after that application. The subjects were asked not to take any solid or liquid food for two hours before giving a saliva sample, which was taken between 10 and 12 o'clock in the morning.

The subjects rinsed their mouths with a $10 \%$ sucrose solution for 30 seconds before $0.1 \mathrm{~mL}$ of saliva was put into $5 \mathrm{mmol} / \mathrm{L}$ iodoacetic acid at $0,2,5,10$, and 20 minutes, as recommended by Sreebny et al. [11]. The sucrose concentration in the saliva was determined using the enzymatic technique defined by Lindfors and Lagerlöf [13] (Boeringer Mannheim $\mathrm{GmbH}$, Germany).

The initial salivary sucrose concentration was described as the sucrose concentration $(\mathrm{mmol} / \mathrm{L})$ two minutes after taking the sucrose. Salivary sucrose clearance time was defined as the time when the sucrose concentration in the saliva dropped below
$5 \mathrm{mmol} / \mathrm{L}$.

\section{Statistical analysis}

The data were analyzed and evaluated using the paired samples t-test in SPSS 11.0 data analysis software.

\section{Results}

Salivary sucrose concentrations before and after placement of the prosthesis are shown in Fig. 1.

The salivary sucrose clearance time and the initial salivary sucrose concentration before and after application of the fixed partial dentures are shown in Table 1. Prior to receiving the prosthesis, the subjects had a sucrose clearance time of $14.88 \pm 0.88$ minutes, which increased to $18.86 \pm 0.91$ minutes after the fixed partial denture were applied. Initial salivary sucrose concentration before receipt of the fixed partial dentures was $113.63 \pm 1.29 \mathrm{mmol} / \mathrm{L}$ and $142.99 \pm 10.82$ $\mathrm{mmol} / \mathrm{L}$ afterwards. Although differences were observed in initial salivary sucrose concentration and salivary sucrose clearance times before and after the fixed partial denture treatments, they were not found to be statistically significant $(p>0.05)$.

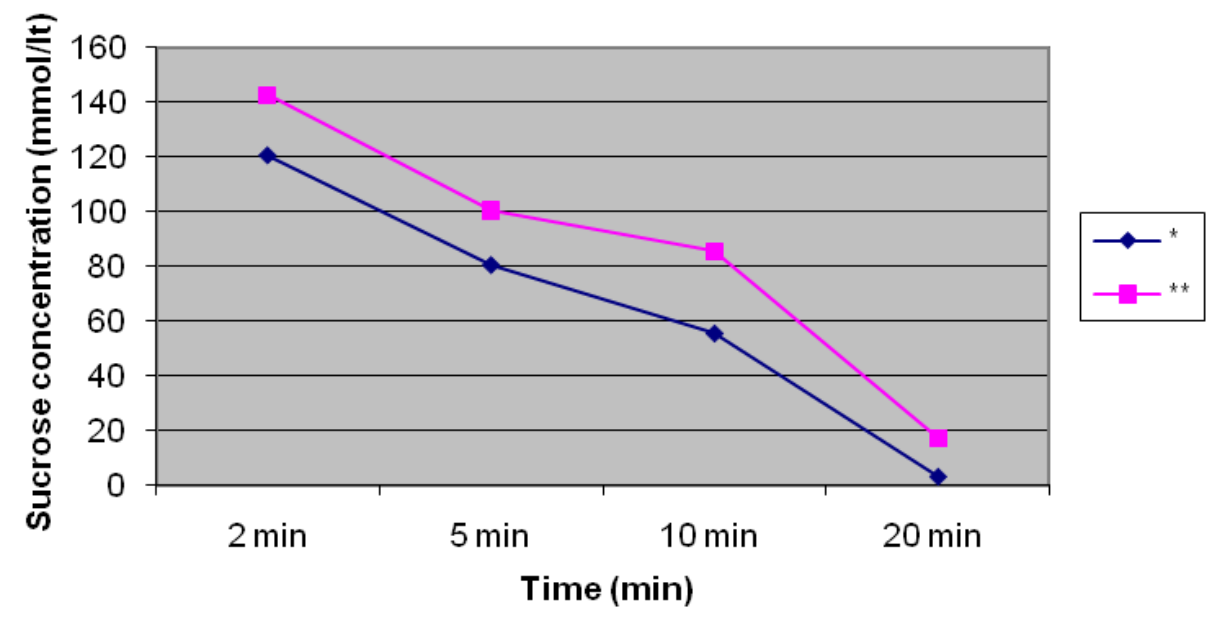

Fig. 1 Concentration of sucrose in saliva before and after application of fixed partial dentures. *before fixed partial dentures, and **after fixed partial dentures.

Table 1. Salivary sucrose clearance time: initial salivary sucrose concentration before and after application of fixed partial dentures.

\begin{tabular}{lllc}
\hline & X \pm SE (minutes) & t-value & P-value \\
\hline *Salivary sucrose clearance & $14.88 \pm 0.88$ & & \\
**Salivary sucrose clearance & $18.86 \pm 0.91$ & -2.25 & 0.15 \\
*Initial salivary sucrose concentration & $113.63 \pm 1.29$ & & \\
**Initial salivary sucrose concentration & $142.99 \pm 10.82$ & -2.50 & 0.13 \\
\hline
\end{tabular}

*before fixed partial dentures, and **after fixed partial dentures. SEM=standard error. 


\section{Discussion}

The occurrence of caries has been attributed to the activity of acidic microbial organisms found in dental plaque. Caries starts with demineralization of the tooth enamel by high concentrations of organic acids that form during fermentation of dietary carbohydrates by plaque bacteria [6]. Accordingly, since dental caries cannot occur in the absence of plaque, the higher the prevalence of plaque in an area, the more caries is seen there. Glazed porcelain is the only prosthetic material that can form a smooth structure. However, it may not be possible to secure an exact smoothness even on the surface of the glazed porcelain [13]. Therefore, oral prostheses form retention fields that increase dental plaque, which increases the risk for caries.

The amount of acid produced by these bacteria varies, depending on the type and concentration of the carbohydrates they can ferment. Sucrose is a sugar commonly used by man that is capable of causing high levels of caries. Exogenic sucrose in in vivo plaque can lead to a sudden decrease in $\mathrm{pH}$, which is accompanied by a increase in lactic acid concentration [14]. The amount of sucrose that can reach the bacteria and the acidogenicity of the plaque, is usually dependent on so-called "sugar-cleaning process" of the saliva or mouth [10,15-17]. Several studies have reported an association between this process and the prevalence of caries $[18,19]$.

Oliveby et al. [20] reported that sucrose concentration in saliva in the second minute following sucrose intake is associated with the lactate concentration in plaque in the twentieth and thirtieth minute. Personal variables that could affect sugar cleaning during this period could be effective in plaque acidogenicity. According to Lagerlöf et al. [21], we used the sugar level in the saliva in the second minute following the intake of sugar to determine the sugarhalving amount. Lagerlöf and Dawes [8] reported that the size of oral cavity could be effective in the sugar cleaning process and that there could even be genderspecific differences in terms of residual volume. Considering this view, only adult males were included in the present study in order to eliminate confounding data with gender effects.

Forsberg et al. [22] could not determine a difference between salivary sugar clearance time before and after the application of an orthodontic appliance. We propose that the absence of a difference might have been caused by the fact that the sugar that is thought to increase the retention of the prosthesis is cleaned from the mouth more rapidly with the increase in the flow rate of saliva. Subjects who use partial and total prostheses reportedly have longer sugar clearance times than those who do not use them. It has been assumed that this result is attributable to a decrease in mouth-muscle coordination and in the ability to bite and masticate after the use of the prosthesis [23]. The fixed partial dentures do not perturb these functions as much as removable dentures. This might explain the inability to distinguish a difference in pre- and post-application sugar clearance times.

Changes in carbohydrate intake can lead to differences in plaque flora. For example, any increase in fermentable carbohydrates leads to an increase in the number of Streptococcus mutans and lactobacilli [6]. Narhi et al. [14] reported that those who wear prostheses have more $S$. mutans and lactobacilli in their mouths than those who still have their natural teeth. Natural teeth have less plaque than the prosthetic teeth. Therefore, attempts must be made to strike a balance between natural and prosthetic teeth in terms of form, shape and function. The dentist and technical staff must be aware of the normal physiologic structure, and its significance and know how to use it [5].

\section{References}

1. LöeH. A rewiev of the prevention and control of plaque. In Mc Hugh WD, Dental Plaque. Edinburgh, Livingstone, 1969; p. 259.

2. Fure S. A ten-year cross-sectional and follow-up study of salivary flow rates and mutans streptococci and lactobacillus counts in elderly Swedish individuals. Oral Health Prev Dent. 2003; 1:185-94.

3. Scheie AA, Arneberg P, Krogstad O. Effect of orthodontic treatment onprevalence of Streptococcus mutans in plaque and saliva. Scand J Dent Res. 1984; 92:211-7.

4. Lundstrom F, Krasse B. Streptococcus mutans and lactobacilli frequency in orthodontic patients: the effect of chlorhexidine treatments. Eur J Orthod. 1987; 9: 109-167.

5. Yavuzyilmaz H. Metal Destekli Estetik (VeneerKaplama Kronlar). Ankara, 1996. p.281.

6. van Houte J. Bacterial specifity in the etiology of dental caries. Int Dent J. 1980; 30:305-9.

7. Hase JC, Birkhed D. Salivary glucose clearance, dry mouth and $\mathrm{pH}$ changes in dental plaque in man. Arch 
Oral Biol. 1988; 12:875-80.

8. LagerlöfF, Dawes C. The volume of saliva in the mounth before and after swallowing. J Dent Res. 1984; 63: 618-21.

9. Crossner CG. Variation in human oral lactobacilli following a change in sugar intake. Scand J Dent Res. 1984; 92: 204-10.

10. Sreebny LM, Chatterjee R, Kleinberg I. Clearance of glucose and sucrose from the saliva of human subjects. Arch Oral Biol. 1985; 30:269-74.

11. Hase JC, Birkhed D, Grennert ML, Steen B. Salivary glucose clearance and related factors in elderly people. Gerodontics. 1987; 3:146-50.

12. Lindfors B, Lagerlöf F. Effect of sucrose concentration in saliva after a sucrose rinse on the hydroniun ion concentration in dental plaque. Caries Res. 1988; 22: 7-10.

13. Craig GR, Powers MJ. Restorative Dental Materials. 11th edition, St. Louis:CV Mosby, 2002. p. 480, 552, 553, 556, 565-566, 576-585.

14. Narhi TO, Ainamo A, Meurman JH. Mutans streptococci and lactobacilli in the elderly. Scand J Dent Res. 1994; 102:97-102.

15. Geddes DAM. Acid produced by human dental plague metabolism in situ. Caries Res. 1975; 9:98-109.

16. Lagerlöf B, Oliveby A, Ekstrand J. Phsiological factors influencing salivary clearance of sugar and fluoride. J Dent Res. 1987; 66:430-5.

17. Dawes C.A mathematical model of salivary clearance of sugar from the oral cavity. Caries Res. 1983; 17 : 321-34.

18. Miura H, Isogai E, Hirose K, Wakizaka H, Ueda I, Ito N. Application of a sucrose indicator to evaluate salivary sucrose clearance. J Dent. 1991; 19:189-91.

19. Adorjan SA, Stack MV. Oral sugar clearance in children. Brit Dent J. 1976; 141:221-2.

20. Oliveby A, Weetman DA, Geddes DA, Lagerlöf F. The effect of salivary clearance of sucrose and fluoride on human dental plaque acidogenicity. Arch Oral Biol. 1990; 35:907-11.

21. Lagerlöf F, Oliveby A, Weetman DA, Geddes DAM. Intra- and inter-individual differences in salivary sucrose clearance over time. Caries Res. 1994; 28 : 348-52.

22. Forsberg CM, Oliveby A, Lagerlöf F. Salivary clearance of sugar before and after insertion of fixed orthodontic appliances. Am J Orthod Dentofacial Orthop. 1992; 102:527-30.

23. Hase JC, Birkhed D. Oral sugar clearance in elderly people with prosthodontic reconstructions. Scand J Dent Res. 1991; 99:333-9. 